\title{
How does the activity level of the parents influence their children's activity? The contemporary life in a world ruled by electronic devices
}

Anna Brzęk ${ }^{1}$, Markus Strauss², Bianca Przybylek², Tarja Dworrak ${ }^{3}$, Birgit Dworrak ${ }^{2}$, Roman Leischik ${ }^{2}$

\begin{abstract}
1Department of Kinesiology, Chair of Physiotherapy, School of Health Sciences, Medical University of Silesia, Katowice, Poland

${ }^{2}$ Faculty of Health, School of Medicine, University Witten/Herdecke, Germany

${ }^{3}$ Department of Biology and Environmental Sciences, Carl von Ossietzky University,

Oldenburg, Germany
\end{abstract}

Submitted: 28 July 2016

Accepted: 22 November 2016

Arch Med Sci 2018; 14, 1: 190-198

DOI: https://doi.org/10.5114/aoms.2018.72242

Copyright @ 2017 Termedia \& Banach

\section{Abstract}

Introduction: Apart from many positive changes associated with technical civilization, there are also - from the health point of view - some threats. The reduction in the level of physical activity is one of them. The aim of the study was to investigate whether there are any relationships between children's physical activity and behaviors, and to assess the impact of the adults' activity on their children's habits.

Material and methods: The study involved a group of 340 children aged 7-12 years (mean age: $9.81 \pm 1.7$ ) and their parents. In order to evaluate children's physical activity and the amount of time that they spend with electronic devices, an original questionnaire and the IPAQ questionnaire were used.

Results: Children usually use electronic devices between 2 and 7 days per week (mean: $4.74 \pm 0.86)$, regardless of $\operatorname{sex}(p>0.09)$ and spend between 5 and 1620 min per week (mean: $459.46 \pm 308.1$ ) with their mobile phone, tablet, PCs and TVs. $67.92 \%$ of boys and $69.61 \%$ of girls lead an active lifestyle. The children's activity level depends on their parents' level of activity $(p<0.000001)$. Parents of semi-active children lead a lifestyle with a moderate level of physical activity.

Conclusions: The level of physical activity in younger children depends on the children's relationship with their parents and their level of activity. Children spend a lot of free time with their electronic devices. It is necessary to develop and implement activities intended to raise awareness of children and their families about the effects of hypokinesis.

Key words: activity, inactivity, obesity, sedentary life, electronic device time.

\section{Introduction}

A decrease of physical activity can be observed worldwide among children, youth and their parents [1, 2]. Sedentary life, especially in a sitting position, is the main cause of inactive lifestyle [3]. Exemplification of parents' habits is very important for young people, especially in the formation of authority [4]. They relate to eating habits, regularity of meals and leisure time activities [5-7]. Development of civilization in the $21^{\text {st }}$ century

\author{
Corresponding author: \\ Anna Brzęk PhD, PT \\ Department of Kinesiology \\ Chair of Physiotherapy \\ School of Health Sciences \\ Medical University \\ of Silesia in Katowice \\ 12 Medyków St \\ 40-754 Katowice, Poland \\ Phone: +48322088721 \\ E-mail: aniabrzek@interia.pl
}


facilitates children's and youths' life at school and at home. Electronic devices are commonly used for homework. Unfortunately, increased usage of electronic devices has its negative sides such as the reduction of physical activities [8, 9], increased body weight, obesity [10-12] and bad body posture habits $[13,14]$. Among the consequences of these body postures, scoliosis for instance stands out $[15,16]$. This can be especially problematic in puberty, for children between 13 and 15 years of age. During research it has been observed that girls exhibit movement laziness which is probably associated with hormonal disorders [17-19]. Different kinds of active hobbies (for example joining sport clubs) are being replaced by spending more time in front of PCs, smartphones and tablets $[7,20]$. A balance between the level of physical activity and the optimum time with devices is recommendable. Deficiency of systematic training often restricts activity and muscle mobility [21]. The consequences are reduction of body tissue and antagonistic muscle contractures. Moreover, it affects the postural stability and can cause body posture problems [22, 23]. Long and permanent akinesia is connected with emerging overweight and obesity. It is a cause of kinesiophobia (fear of any form of movement) [24]. Kinesiophobia combined with sedentary life is the cause of a "vicious circle". This vicious circle can affect the cardiovascular and respiratory systems [11]. Additionally, these problems can increase when children copy other children's behavior because of the public pressure and the urge to gain acceptance. Therefore, it is a phenomenon that affects large groups of school children [4]. The research questions are focused on the reasons for the lack of physical activity, and the possibility of preventing and effectively promoting a healthy lifestyle. These questions are of scientific and societal relevance, because they are still unsolved. The problem of physical activity reduction was a very important question that emerged while the hypothesis for this study was being created. This problem has been identified but not yet solved. The research presented in this study is only a part of a larger scientific project.

The following questions were posed:

1. How many hours do the children spend with their electronic devices?

2. To what extent do children conduct physical activity? And on what does it depend?

3. What is the influence of the non-active time on the physical ability?

4. To what extent do the parents conduct physical ability? On what does it depend?

5. How does the parents' activity influence their children's physical level?

The aim of this study was to evaluate the level of children's physical activity and its association with their parents' physical activity. Furthermore, this study assesses the relationship between body weight characteristics of school children and their parents.

\section{Material and methods}

\section{Ethics statement}

This study was approved by the Ethics Committee of the Medical University of Silesia under resolution no. KNW/0022/KB1/162/10 and conformed to the Declaration of Helsinki. All of the participants (children's parents) provided written informed consent prior to the study, including enrollment and data collection.

\section{Methods}

The present study was a prospective cohort study in which a group of school children in elementary schools in the region of Silesia in Poland were examined. The investigation started in 2011 and ended in 2016. Examinations were conducted in two groups: group A focused on children and group B focused on their parents. The sample size was calculated by using the sample size calculation for proportions. The sample size was 340 [25].

The study involved a group of 340 school children at early school age - between 7 and 12 years old (mean age: $9.81 \pm 1.7)$. One hundred eighty-one (53.23\%) female participants and 158 (46.76\%) male participants exhibited healthy body posture diagnosed on the basis of prophylactic examinations. Accordingly, the following exclusion criteria were important for this study: below the age of 7 or above the age of 12 , exempted from physical education classes because of frequent infections or orthopedic injuries, scoliosis, unstable asthma; a "growth spurt" was detected among excluded children, and this could have influenced the results of the posture evaluation. Group B consisted of 340 children parents aged between 23 and 47 years (mean age: $32.12 \pm 3.99$ ) and among them 193 (56.76\%) were children's mothers and 147 (43.24\%) were children's fathers.

\section{Data collection}

In the examined group of children, length and weight of the body were measured, and body mass index (BMI) was calculated and further interpreted as a BMI percentile [26-29]. The adults' weight and height were measured and BMI was also calculated. Each group answered questions about their physical activity and how much time they spend with electronic devices. Questions in the author's questionnaire concerned the possible use of a mobile phone, tablet, PC, computer games 
at home and at school, during weekdays and weekends. Reported individual time (in minutes) referred to the amount of time which participants spent with each electronic device, separately and in total. For this purpose the IPAQ (International Physical Activity Questionnaire - long form) was used to measure the level of physical activity in four domains: physical activity connected with professional work (school activity), housework, backyard work, activity connected with transport and free time activity. Furthermore, activities listed in IPAQ are divided as follows: low intensity - mainly walking (energy output value 3.3 MET, indicated by the letter $W$ ); moderate intensity (4.0 MET, indicated by M); high intensity (8.0 MET, indicated by $\mathrm{V})$. The fifth domain concerns the time spent in a sedentary position, and this domain is expressed in minutes. Based on the IPAQ, the level of physical activity among adults involved in the tests was calculated (low, moderate, high) in all of the above-mentioned domains.

\section{Statistical analysis}

The obtained data were analyzed separately for each examined group. Clinical characteristics, weight, height, and BMI were described by the mean value, standard deviation and minimum and maximum values. Differences between groups were estimated by linear regression adjusted for age since most of the analyzed parameters are directly age-related and the $95 \%$ confidence interval $(\mathrm{Cl})$. The relationships between particular results were assessed sequentially, and the results are shown as a number (\%), mean ( $x$ ) and standard deviation (SD). Subsequently, the differences between the parameters obtained in both groups were described. For data analysis the following statistical methods were used: Mann-Whitney $U$ test for continuous variables with non-normal distribution, Student's $t$ test for continuous variables with normal distribution to assess relationships between examinations, and for non-parametric characteristics the $\chi^{2}$ test and Spearman's rank test. A normal distribution was verified by the Kolmogorov-Smirnov test. All of the statistical tests were significant at the level of 0.05 . Statistica v.10 and Excel were used for statistical analysis.

\section{Results}

\section{Overall characteristics of examined groups}

A preliminary review of the database did not reveal any characteristic results among the examined groups aside from several unique individual results. The groups were homogeneous, and no statistically significant difference in age between the group of girls and boys was noted. Group A was divided by gender, weight and BMI classi- fication into normal weight and overweight. The groups are similar in terms of numbers. $59.59 \%$ of women (children's mothers) and $47.62 \%$ of men (children's father) had a normal weight range between $18.5 \mathrm{~kg} / \mathrm{m}^{2}$ and $24.99 \mathrm{~kg} / \mathrm{m}^{2}$ based on the BMI classification. Only $7.77 \%$ of women were classified as underweight. There was a significant difference in weight between women and men $(p<0.0001)$.

\section{The time children spend with electronic devices}

The examined children have been using electronic devices regularly each day. The youngest participants who used a mobile phone or tablet ranged between the age of 2 and 9 years (mean: $5.24 \pm 1.65$ years). There was no significant difference between girls and boys $(t=0.08 ; p>0.92)$. The time of use of electronic devices which were used ranged between 2 and 7 day per week (mean: $4.74 \pm 0.86)$ regardless of gender $(p>0.09)$. The amount of hours in front of a TV, computer, tablet or mobile phone was gender neutral and ranged between 5 and 1620 min per week (mean: $459.46 \pm 308.1 \mathrm{~min}$ ). There was a significant difference between girls and boys $(t=1.09 ; p>0.27)$. For instance, boys had a tendency to spend a lot of time in front of the PC. This tendency did not depend on age $(p>0.05)$. In contrast, girls spent more time and more often on Internet portals such as Facebook $(t=4.09 ; p<0.00005)$ (Table I).

Overweight children spend more time during the week with computer devices than their colleagues with normal weights; 533.94 vs. 411.6 $(p<0.0003)$. In each group, this tendency changes linearly with age (all $p<0.002$ ).

Watching TV affects all of the groups $(p>0.17)$. One hundred and seventy-eight (98.34\%) girls spend between 5 and 720 min on watching TV during the week (mean time: $112.45 \pm 101.19$ ). Boys spend between 5 and 600 min on watching TV during the week (mean time: $116.54 \pm 107.98$ ).

\section{Students' perception of how often they have to use devices}

$40.28 \%$ of girls and $46.43 \%$ of boys shared the opinion that "life without electronic devices like tablets, computers, mobile phones, and Facebook does not make any sense". In each group, this tendency changes linearly with age $(p<0.018)$. $84.28 \%$ of boys and $81.22 \%$ of girls use their mobile phone everywhere: in the classroom, in the washroom, during school trips and at night. $50.31 \%$ of boys and $47.51 \%$ of girls use their phone on their walk to school. This situation can be dangerous. $64.46 \%$ of these students are crossing the streets. Then they were asked if they knew 


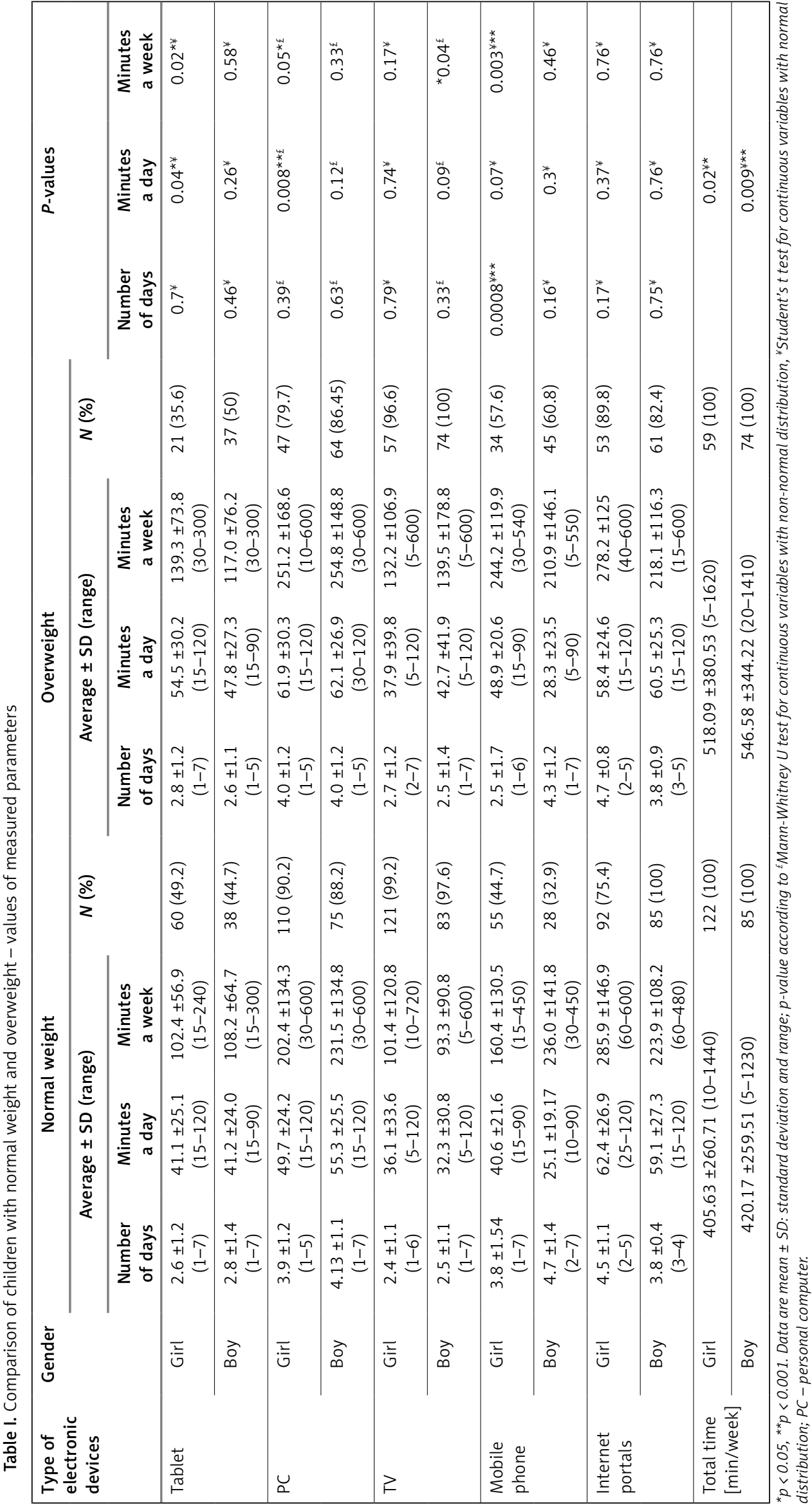


how dangerous this situation is. Most of them replied 'Yes, but I do it very often'. This statement does not depend on their age $(p>0.52) .78 .51 \%$ of the children had a profile on Internet portals such as Facebook or Instagram. The profile depended on their age (Spearman's $R=0.15, p<0.004$ ). As many as $33.58 \%$ of examined children use these portals without their parents' permission.

\section{Children's behavior after a limited time to use the electronic devices}

$37.11 \%$ of boys and $33.15 \%$ of girls have to ask their parents for additional time to use the computer or tablet after their prescribed time is over. Only $28.93 \%$ of boys and $30.39 \%$ of girls always follow the parents' commands and always turn off the devices. The reactions to limited time differed: $8.18 \%$ of boys reacted aggressively $(12.15 \%$ of girls), $5.66 \%$ started to cry ( $2.76 \%$ of girls), and $16.35 \%$ extended the time by keeping on playing in the washroom or during homework $(13.81 \%$ of girls). There is no difference between examined groups $\left(X^{2}=7.76, \mathrm{~d} f=8, p>0.46\right)$. If children asked their parents about the possibility to extend this time, $39.11 \%$ of parents answered 'Yes', $45.88 \%$ of them answered 'No' and 15\% of parents answered 'Sometimes'. Parents' decisions are not associated with the gender of their children $(p>0.22)$ or their weight $(p>0.16)$. Fathers answered 'Yes' more often than mothers $-65.71 \%$ vs. $10.91 \%$ ( $p<0.00001)$. Women (children's mothers) stated that they do not extend the time for the devices $\left(X^{2}=7.92, \mathrm{~d} f=1, p<0.002\right) .63 .64 \%$ of them said 'No' to children with normal weight and $71.21 \%$ of them said 'No' to overweight children.

\section{Children's physical activity}

\section{Declared activity versus factual activity}

Declared activity means answering 'Yes' to the question "Do you think that your child conducts active life?". Actual activity is based on the analysis of the various sport types, training frequencies and times. A child is determined as active when she/he practices a sports activity accompanied by a professional trainer two times a week. Semi-active means practicing sport one time per week and guided by their parents. Non-active means that the interviewee practices sports irregularly or reports the absence of any activity. $67.92 \%$ of boys' parents and $69.61 \%$ of girls' parents declared that their children live an active life. This activity depends on weight (Spearman's $R=0.14, p<0.046$ ) in the girls' group. Girls with normal weight (50.25\% - boys: $82.35 \%$ ) are much more active than overweight girls (19.34\% - boys: $51.35 \%)$. Boys with normal weight declared that they are active in $82.35 \%$, while overweight boys declared being active in 51.35\% ( $p<0.0002)$. A detailed analysis showed that the distribution was different than that declared by the children's parents ( $p<0.00001) .35 .88 \%$ of children are active $(15 \%$ of boys; $20.88 \%$ of girls), $23.24 \%$ are semi-active (12.35\% of boys; $10.88 \%$ of girls) and $40.88 \%$ are non-active (19.41\% of boys; $21.47 \%$ of girls). The level of activity depends on their age $(p<0.00001)$. Younger children are more inactive than their older colleagues. Overweight and the children's status of activity correlate negatively with each other $(p<$ 0.002). Children spend their free time (after school time) on: swimming, football, basketball and volleyball. The types of practiced sports are different for girls and boys ( $p<0.003)$; girls prefer dancing and volleyball, while boys prefer football and basketball as well as a combination of different sport activities. Children started their activity between 2 and 96 months (mean: $36.24 \pm 20.99$ months). Frequency of physical activity ranged between 1 and 4 days per week (mean: $2.14 \pm 0.8$ ), and length of one training unit ranged between 15 and $120 \mathrm{~min}$ (mean: $61.48 \pm 22.9 \mathrm{~min}$ ). Fifteen percent of the examined children do not like the physical education lessons but they attend classes regularly.

\section{Sitting position}

From Monday to Friday examined children spend their time in a sitting position; the amount of time ranged between 5 and $10 \mathrm{~h}$ (mean: 7.49 $\pm 1.09 \mathrm{~h}$ ). At school they spend from 4 to $6 \mathrm{~h}$ in a sitting position (mean: $4.84 \pm 0.47 \mathrm{~h}$ ) and at home from 1 to $5 \mathrm{~h}$ in the sitting position (mean: 2.65 $\pm 0.92 \mathrm{~h})$. Children's age $(R=0.07, p>0.88)$ and $\operatorname{sex}\left(X^{2}=4.39, \mathrm{~d} f=5, p>0.49\right)$ did not affect the results. During the weekend boys and girls spend much more time in a sitting position than during the school week. The amount of time ranges between 2 and 9 h (mean: $5.03 \pm 1.65$ h). $64.61 \%$ of overweight children $37 \%$ of the children with normal weight) spend between 5 and $9 \mathrm{~h}$ in a sitting position ( $\left.X^{2}=17.17, \mathrm{~d} f=7, p<0.016\right)$. Active children spend much less time in this position than non-active and semi-active children $(p<0.00001)$ A correlation between sitting hours and time spent with electronic devices was found.

\section{Level of adults' physical activity}

In $26.42 \%$ of women and only $33.33 \%$ of men a high AF level was noted. The levels of physical activity among the examined groups in particular domains according to the IPAQ are shown in Table II. No significance was observed in two domains: job and "leisure time". Physical activity level depends on age (Spearman's $R=-0.52, p<$ 0.00001 ) and BMI coefficient only in men groups (Spearman $R=-0.26, p<0.001$ ). Additionally, it was found that women spend their time in a sit- 
ting position on average from 75 to $720 \mathrm{~min} /$ day (mean: $364.97 \pm 180.12 \mathrm{~min})$. Men spend between 75 and $720 \mathrm{~min} /$ day in this position (mean: $385.88 \pm 173.79 \min (t=2.0, p<0.03))$. During weekends this time ranges between 54 and $1440 \min (t=2.12 ; p<0.03)$. One hundred percet of examined parents travelled primarily by car from 1 to $5 \mathrm{~h}$ a day (mean: $2.25 \pm 0.82 \mathrm{~h}$ during 1-7 days a week). Women spend less time in the car than men $(t=8.08, p<0.00001)$.

\section{Children's level of activity versus parents' activity level}

More than $40 \%$ of the examined children lead an inactive life $(40.33 \%$ of girls and $41.51 \%$ of boys). Parents' activity is on a moderate level; only $19.69 \%$ of women and $12.24 \%$ of men practice a low level of physical activity. One hundred percent of the semi-active children's parents have a moderate activity level. $78.69 \%$ of the active parents have active children (Table III). Children's activity level depends on the activity of their parents $(p<0.00001)$. Parents' activity has an impact on children's total time with electronic devices (Table IV).

\section{Discussion}

The purpose of this study was to determine the level of physical activity in younger children and to assess the relationship to their parents' activity. $88.52 \%$ of children duplicate their parents' habits. The gender of children did not reveal any significant influence.

Over the years, scientists have been observing the sedentary life [4-7, 11], which among adults is basically a norm, whereas in children it is a novelty. Physical activity in children and adolescents decreases as more and more of them prefer to

Table II. Level of physical activity of children's parents in particular domains according to IPAQ

\begin{tabular}{|c|c|c|c|c|c|}
\hline \multirow[t]{2}{*}{ IPAQ domain } & \multicolumn{2}{|c|}{ Women (mothers) } & \multicolumn{2}{|c|}{ Men (fathers) } & \multirow[t]{2}{*}{$\mathrm{T}$} \\
\hline & Average \pm SD & Range & Average \pm SD & Range & \\
\hline Job-related [MET-min/week] & $9653.94 \pm 6900$ & $0-29400$ & $10609.9 \pm 7471.25$ & $0-29400$ & 1.33 \\
\hline Housework [MET-min/week] & $2097.06 \pm 2015.24$ & 0-9702 & $1616.22 \pm 1358.84$ & 0-9702 & $2.49^{a}$ \\
\hline Transportation [MET-min/week] & $1716.51 \pm 1655.38$ & $0-7650$ & $2049.67 \pm 1776.3$ & $0-6240$ & 1.67 \\
\hline Leisure time [MET-min/week] & $2193.37 \pm 2175.66$ & $0-7824$ & $2249.59 \pm 2138.6$ & $0-7824$ & 0.23 \\
\hline Total time sitting [min/week] & $1791.29 \pm 1053.85$ & $250-4200$ & $1972.52 \pm 1219.67$ & $250-4200$ & 1.43 \\
\hline $\begin{array}{l}\text { Weekend total time sitting } \\
{[\mathrm{min} / \text { weekend] }}\end{array}$ & $689.03 \pm 316.71$ & $15-120$ & $765.65 \pm 346.85$ & $30-120$ & $2.12^{\mathrm{a}}$ \\
\hline $\begin{array}{l}\text { Average total time sitting } \\
\text { [min/week] }\end{array}$ & $364.97 \pm 180.12$ & $30-600$ & $385.88 \pm 173.79$ & $30-600$ & 1.07 \\
\hline $\mathrm{MET} / \mathrm{min} /$ week & $9341.78 \pm 6700.81$ & $0-35004$ & $11339.34 \pm 7591.05$ & $0-37152$ & $2.57^{a}$ \\
\hline $\mathrm{MET} / \mathrm{min} / \mathrm{day}$ & $1334.54 \pm 957.26$ & $0-5000.57$ & $1619.91 \pm 1084.43$ & $0-5307.43$ & $2.57^{\mathrm{a}}$ \\
\hline
\end{tabular}

${ }^{a} p<0.05 ;{ }^{b} p<0.01$. Data are mean $\pm S D$ : standard deviation and range (min-max); IPAQ - International Physical Activity Questionnaire, MET - metabolic equivalent of work.

Table III. Distribution materials by level of activity in children's group according to parents' activity level

\begin{tabular}{|c|c|c|c|c|c|c|c|}
\hline \multicolumn{2}{|c|}{ Level of activity } & \multicolumn{3}{|c|}{ Girls, $N(\%)$} & \multicolumn{3}{|c|}{ Boys, $N(\%)$} \\
\hline & & Inactive & Semi-active & Active & Inactive & Semi-active & Active \\
\hline \multirow[t]{3}{*}{ Women } & Low & $24(22.02)$ & - & - & $14(16.67)$ & - & - \\
\hline & Moderate & $19(17.43)$ & $23(21.1)$ & $14(12.84)$ & $20(23.81)$ & $21(25)$ & $7(8.33)$ \\
\hline & High & $4(3.67)$ & - & $25(22.94)$ & - & - & $22(26.19)$ \\
\hline$X^{2} ; \mathrm{d} f ; p$ & & \multicolumn{2}{|c|}{$77.67 ; 4 ;<0.00001$} & & \multicolumn{3}{|c|}{$74.6 ; 4 ;<0.00001$} \\
\hline \multirow[t]{3}{*}{ Men } & Low & $8(11.11)$ & - & - & $10(13.33)$ & - & - \\
\hline & Moderate & $18(25)$ & $14(19.44)$ & $4(5.56)$ & $22(29.33)$ & $21(28)$ & $1(1.33)$ \\
\hline & High & - & - & $28(38.89)$ & - & - & $21(28)$ \\
\hline$X^{2} ; \mathrm{d} f ; p$ & & \multicolumn{2}{|c|}{$67.07 ; 4 ;<0.00001$} & & \multicolumn{3}{|c|}{$81.68 ; 4 ;<0.00001$} \\
\hline
\end{tabular}


Table IV. Correlation between the level of parents' physical activity and children's total time spent with electronic devices

\begin{tabular}{|lcccccc|}
\hline Variable & \multicolumn{3}{c}{ Girls } & & Boys \\
\cline { 2 - 7 } & $R$ & $R^{2}$ & $P$-value & $R$ & $R^{2}$ & $P$-value \\
\hline Women (mothers) & -0.17 & 0.03 & $0.04^{*}$ & -0.18 & 0.03 & 0.05 \\
\hline Men (fathers) & -0.42 & 0.17 & $0.0009^{* *}$ & -0.17 & 0.03 & 0.27 \\
\hline${ }^{*} p<0.05^{* *} p<0.001 ; R$ - correlation coefficient, $R^{2}$-coefficient of determination.
\end{tabular}

spend their leisure time passively, in front of TVs or PCs [30]. Over the past years, electronic devices have been becoming more easily available. Possibilities to use the devices (e.g. tablet, laptop and mobile phone) in other positions than sitting can be a cause of bad body posture [4, 20, 23]. These positions are predominantly not ergonomic. That kind of behavior may contribute to the decrease of physical activity among children, and it may also be a cause of overweight and obesity [11, 31-34]. This can be more dangerous for children because vital activity is physically required for proper psychomotor development [4, 21, 35]. Reduced participation in physical activity $[8,10,11$, 17], especially during this time of transition from a dynamic to a static lifestyle, may itself cause an imbalance in the tension of antagonist postural muscles and may lead to serious posture disorders. This can also influence the children in their adulthood. It will affect the quality of life (QoL). In 2009-2010 the quality of children's life was determined; children from Canada, Germany, Portugal, USA, Lithuania, Poland, Romania, and Slovakia are in the lower position in the table presented by the World Health Organization (WHO) [36]. Representatives of the evaluated countries claim that taking care of young generations is an investment in future societal health. Based on the results of international research on health behavioral patterns in children and adolescents (HBSC - Health Behaviour in School-aged Children. WHO Collaborative Study 2010) $44.4 \%$ of school-age children spend $4 \mathrm{~h}$ in front of the TV screen during the days off from school. $35.5 \%$ of the students practice physical activity at a recommended level $[1,2,37]$.

The physical activity guidelines (at least $1 \mathrm{~h}$ per day of moderate-to-vigorous physical activity (MVPA) - recommended by the WHO) are significantly more frequently used among 11-year-olds than 15-year-olds in almost every country and region. Boys tend to get at least 60 min of MVPA per day. Gender differences are significant in many countries and regions across all age groups [36]. Only $35.88 \%$ of children (distribution half girls, half boys) and $29.41 \%$ of parents live a life with a high physical activity level. According to the WHO results, less active children live in Switzerland, France, Denmark and Italy. Children with moderate activity levels are from such countries as Poland, Germany, Slovenia and Hungary. The most active children aged from 11 to 15 live in Ireland, Austria and the USA. This is striking, since the USA has the highest percentage of overweight and obese children [36].

Sedentary behaviors can result in health complaints. Children who spend more time with electronic devices tend to be more aggressive [36, 37]. $10.29 \%$ of the examined children reacted aggressively or sad when their time with the electronic devices ended. $15 \%$ of children kept on playing secretively. However, then their stress level increased. Current recommendations suggest that children should not sit for more than 1 to $2 \mathrm{~h}$ in front of a TV (including videos, DVDs, using the mobile phone and tablet) per day [37].

In our experience, children spend much more time than recommended. Their time spent with devices ranges between 1 and $5 \mathrm{~h}$ per day and 2 to $9 \mathrm{~h}$ during weekends [38].

The elimination of electronic devices is not possible because nowadays electronics and their usage are increasing and are becoming indispensable for mental development. Although there are some simple methods to solve this problem, they require a high level of control (parents, legal guardians or teachers). Our examination showed that $46.47 \%$ of children started using mobile phones, tablets or PCs before reaching school age. Fifteen percent of children played on their parents' mobile phone before they were 3 years old. Over $50 \%$ of examined parents agreed to extend the electronic devices time. $82.64 \%$ of children use electronic devices everywhere (at school, in the washroom, on their way to school). $53.83 \%$ of children are using internet portals such as Facebook without their parents' permission. It should be mentioned that according to the Regulations of Facebook, an account can be created by a person after completing 13 years of age [39].

Because of these unsatisfactory results throughout the years, the prophylactic program 'my healthy spine at school' was developed in Poland. The children's parents were also instructed how to spend their free time with their children, and about why the time spent with electronic devices is associated with the body posture and its 
possible disabilities. The spine protection program is indispensable, because sedentary lifestyles increase the rate of postural defects which occur during development from youth to adolescence in activity patterns $[4,40]$.

The data from 6 years of practical studies have been collected for further research and analysis these data can help to develop an ideal strategy to reduce or even eliminate the time spent with electronic devices and replace it with physically active time with their parents.

In conclusion, in the electronic world too much time is spent with electronic devices. Children and their parents spend a lot of time in a sitting position. The consequence is that children have a wrong opinion about physical activities. As proved by the questionnaire, most of the interviewees believed that their activity is higher than it actually is. The parents' level of activity affects the children's activity level. Other influencing factors such as overweight, age, and gender are determinants of children's activity. Children are likely to adopt their parents' habits in adulthood. Thus, it is necessary to implement long-term prevention programs which affect the entire family. Worldwide, the risk of children becoming more inactive and unhealthy is increasing among children, who are adept at using new electronic devices. In our opinion, a balance between the usage of electronic devices and physical activity on a daily basis is indispensable.

\section{Acknowledgments}

The authors wish to thank Weronika GallertKopyto for proofreading the manuscript in professional English Language.

\section{Conflict of interest}

The authors declare no conflict of interest.

\section{References}

1. Bobakova D, Hamrik Z, Badura P, Sigmundova D, Nalecz H, Kalman M. Test-retest reliability of selected physical activity and sedentary behaviour HBSC items in the Czech Republic, Slovakia and Poland. Int J Public Health 2015; 60: 59-67.

2. Iannotti RJ, Janssen I, Haug E, Kololo H, Annaheim B, Borraccino A. Interrelationships of adolescent physical activity, sedentary behaviour, and positive and negative social and psychological health. Int J Public Health 2009; 54: 191-8.

3. William B, Strong WB, Malina RM. Evidence based physical activity for school-age youth. J Pediatr 2005; 146: 732-7.

4. Brzęk A, Plinta R. Exemplification of movement patterns and their influence on body posture in younger schoolage children on the basis of an authorial program "I Take Care of My Spine". Medicine 2016; 95: e2855.

5. Cliff DP, Hesketh KD, VellaS A, et al. Objectively measured sedentary behaviour and health and develop- ment in children and adolescents: systematic review and meta-analysis. Obes Rev 2016; 17: 330-44.

6. Biddle SJH, Gorely T, Marshall SJ, Cameron N. The prevalance of sedentary behavior and physical activity in leisure time: a study of Scottish adoloscent using ecological momentary assessment. Prev Med 2009; 48: 151-5.

7. Chinapaw M, Altenburg T, Burg J. Sedentary behavior and health in children. Evaluating the evidence. Prev Med 2015; 70: 1-2.

8. Sherar LB, Griffin TP, Ekelund U, et al. Association between maternal education and objectively measured physical activity and sedentary time in adolescents. J Epidemiol Community Health 2016; 70: 541-8.

9. Ekelund U, Fau-Luan J, Luan J, et al. Moderate to vigorous physical activity and sedentary time and cardiometabolic risk factors in children and adolescents. JAMA 2012; 307: 704-12.

10. Salonen MK, Wasenius N, Kajantie E, et al. Physical activity, body composition and metabolic syndrome in young adults. PLoS One 2015; 10: e0126737.

11. Leischik R, Foshag P, Strauss M, et al. Physical activity, cardiorespiratory fitness and carotid intima thickness: sedentary occupation as risk factor for atherosclerosis and obesity. Eur Rev Med Pharmacol Sci 2015; 19: 3157-68.

12. Dias KA, Green DJ, Ingul CB, Pavey TG, Coombes JS. Exercise and vascular function in child obesity: a meta-analysis. Pediatrics 2015; 136: e648-59.

13. Weinstein SL, Dolan LA, Spratt KF, et al. Health and function of patients with untreated idiopathic scoliosis: a 50-year natural history study. JAMA 2003; 285: 559-67.

14. Widmann RF, Bitan FD, Laplaza FJ, Burke SW, DiMaio MF, Schneider R. Spinal deformity, pulmonary compromise, and quality of life in osteogenesis imperfecta. Spine 1999; 24: 1673-8.

15. Hawes MC, O'Brien JP. The transformation of spinal curvature into spinal deformity: pathological processes and implications for treatment. Scoliosis 2006; 1: 3.

16. Weiss HR, Negrini S, Hawes MC, et al. Physical exercises in the treatment of idiopathic scoliosis at risk of brace treatment. Scoliosis 2006; 1: 6.

17. Cosma G, Ilinca I, Rusu L, Nanu C, Burileanu A. Physical exercise and its role in a correct postural alignment. Discobolul Physcal Educ Sport Kinetother J 2015; 11: 58-64.

18. Wroman KG. Childchood and adoloscent obesity. In: Pediatric skills for occupational therapy assistans. Salomon JW, O'Brien JC (eds). Elsevier Inc, Philadelphia 2016; 277-95.

19. Lemos AT, Santos FR, Gaya AC. Lumbar hyperlordosis in children and adolescents at a privative school in southern Brazil: occurrence and associated factors. Cad Saude Publica 2012; 28: 781-8.

20. Verloigne M, Van Lippevelde, Maes L, et al. Self-reported TV and computer time do not represent accelerometer-derived total sedentary time in 10 to 12 -year-olds. Eur J Public Health 2012; 23: 30-2.

21. Brzęk A, Famuła A, Sołtys J. The formation of motor abilities in the process of ontogenesis. Theoretical aspects and practical guidelines. $1^{\text {st }}$ ed. Katowice (PL), SUM Ed 2013.

22. Miñana-Signes $V$, Monfort-Pañego M. Knowledge on health and back care education related to physical activity and exercise in adolescents. Eur Spine J 2016; 25: 755-9.

23. Mitchell E, Beasley R, Björksten B, Crane J, Gracia-Markos L, Keil U, ISAAC Phase Three Study Group. The as- 
sociation between $\mathrm{BMI}$, vigorous physical activity and television viewing and the risk of symptoms of asthma, rhinconjuntivitis and eczema in children and adoloscent: ISAAC phase three. Clin Exp Allergy 2012; 43: 73-84.

24. Knapik A, Saulicz E, Gnat R. Kinesiophobia - introducing a new diagnostic tool. J Human Kinetics 2011; 28: 25-31.

25. http://www.raosoft.com/samplesize.html

26. Javed A, Jumean M, Murad MH. Diagnostic performance of body mass index to identify obesity as defined by body adiposity in children and adolescents: a systematic review and meta-analysis. Pediatr Obes 2015; 10: 234-44.

27. Jodkowska M, Woynarowska B, Oblacińska A. A screening test for the abnormalities' detection in the physical development of children and adolescents in school age. Warszawa (PL): Ezdorat Ed 2007.

28. http://www.who.int/growthref/en/

29. Pate RP, Pratt M, Blair SN, et al. Physical activity and public health. A recommendation from the Centers for Disease Control and Prevention and the American College of Sports Medicine. JAMA 1995; 273: 402-7.

30. Pokrywka J, Fugiel J, Posłuszny P. Prevelance of postural disorders in children from Copper Basin in Poland. Fizjoterapia 2011; 19: 3-10.

31. Maddison R, Foley L, Ni Mhurchu C, et al. Effects of active video games on body composition: a randomized controlled trial. Am J Clin Nutr 2011; 94: 156-63.

32. Ostojic SM, Stojanovic MD, Stojanovic V, Maric J, Njaradi N. Correlation between fitness and fatness in 6-14 year old Serbian school children. J Health Popul Nutr 2011; 29: 53-60.

33. Nathan N, Wolfenden L, Williams CM. Educational interventions are effective in treating childhood obesity: (PEDro synthesis). Br J Sports Med 2016; 50: 130-1.

34. Leischik R, Dworrak B, Strauss M, et al. Plasticity of health. German J Med 2016; 1: 1-17.

35. Pate RP, Pratt M, Blair SN, et al. Physical activity and public health. A recommendation from the Centers for Disease Control and Preventon and the America College of Sports Medicine. JAMA 1995; 273: 402-7.

36. Global recommendations on physical activity for health. Geneva. World Health Organization 2010. Accessed 23 February 2012.

37. Currie C, Zanotti C, Morgan A, et al. Social determinants of health and well-being among young people. Heal the Behaviour in school-aged Children (HBSC) Study International Report from the 2009/2010 Survey.

38. Canadian Paediatric Society. Impact of media use on children and youth. Paediatrics and Child Health 2003; 8: 301-6.

39. https://www.facebook.com/legal/terms

40. Brzęk A, Dyrda B, Nowotny-Czupryna O, Jachacz-topata $M$. Postural defects prevention programme as the exemplification of actions in the scope of health promotion in early school education - an action research perspective. New Educ Rev 2011; 24: 194-204. 